\title{
Effects of pill splitting training on drug physiochemical properties, compliance, and clinical outcomes in the elderly population: a randomised trial
}

\author{
Vivian WY Lee *, Joyce TS Li, Felix YH Fong, Bryan PY Yan
}

This article was published on 11 Jun 2021 at www.hkmj.org.

\section{A B S T R A C T}

Introduction: This study aimed to provide information about the clinical and physiochemical effects of pill splitting training in elderly cardiac patients in Hong Kong.

Methods: A parallel study design was adopted. Patients taking lisinopril, amlodipine, simvastatin, metformin, or perindopril who needed to split pills were recruited from the Prince of Wales Hospital. Patients were divided into two groups at their first visit. Patients in group A split drugs using their own technique, whereas patients in group B used pill cutters after relevant training until their next follow-up visit. The primary outcome was the change in drug content between before and after the pill splitting training. Assays were performed to determine the drug content. Secondary outcomes were the changes in clinical outcomes, patients' attitudes and acceptance towards pill splitting, and patients' knowledge about pill splitting.

Results: A total of 193 patients were recruited, and 101 returned for the follow-up visit. The percentage of split tablets falling within the assay limits increased from $39.13 \%$ to $47.82 \%(\mathrm{P}=0.523)$ in group

The changes did not reach statistical significance. As for clinical outcomes, the mean triglyceride level decreased from $1.62 \pm 1.05$ to $1.36 \pm 0.80 \quad(P=0.049)$, whereas the mean heart rate increased significantly from $73.97 \pm 11.01$ to $77.92 \pm 12.72(\mathrm{P}=0.026)$. Changes in other parameters were not significant.

Conclusion: This study highlights the high variability of drug content after pill splitting. Pills with dosages that do not require splitting would be preferable, considering patients' preference. Patients should be educated to use pill cutters properly if pill splitting is unavoidable.

\section{Hong Kong Med J 2021;27:184-91 https://doi.org/10.12809/hkmj208455}

\section{${ }^{1}$ VWY Lee *, PharmD, BCPS \\ ${ }^{1} \mathrm{JTS}$ Li, BPharm \\ ${ }^{1}$ FYH Fong, BPharm \\ ${ }^{2}$ BPY Yan, FHKAM (Medicine)}

${ }_{1}^{1}$ Centre for Learning Enhancement and Research, The Chinese University of Hong Kong, Hong Kong

Department of Medicine and Therapeutics, The Chinese University of Hong Kong, Hong Kong

A and from $48.94 \%$ to $51.06 \%(\mathrm{P}=1.000)$ in group B. * Corresponding author: vivianlee@cuhk.edu.hk

New knowledge added by this study

- There is high variability of drug content after pill splitting.

- Patients prefer to take pills that do not require splitting.

Implications for clinical practice or policy

- Patients should be supplied with formulations that do not require splitting if possible.

- Patients should be educated to use pill cutters properly if pill splitting is unavoidable.

\section{Introduction}

Pill splitting by patients is common globally. A German study observed that $24.1 \%$ of all drugs required splitting, ${ }^{1}$ and a Swiss study found that $10 \%$ of all discharged prescriptions contained pill splitting. ${ }^{2}$ In Sweden, 10\% of 600000 investigated prescriptions required splitting, and over $30 \%$ of the Swedish patients stated that they had problems dividing the tablets. ${ }^{3}$ The observed prevalence of pill splitting has been observed to range from $10 \%$ to $>35 \%$ worldwide ${ }^{1,4-6}$ and was even higher in elderly patients (35-67\%). ${ }^{6,7}$ One of the reasons for pill splitting is cost saving because it may result in institutions not needing to stock too many drug items in their formularies. ${ }^{1}$ In addition, drug splitting may achieve dose flexibility, particularly for patients requiring frequent dosing adjustment. ${ }^{8}$ Furthermore, some dosages may not be commercially available, especially those for off-label drug use. In these cases, splitting drugs may be essential. ${ }^{9-11}$ Nevertheless, it can also create other clinical issues including medication non-compliance, difficulties experienced by patients in handling unscored pills, drugs that crumble after splitting, and inappropriate 
drug splitting of extended release formulations, which may lead to treatment failure or toxicity. ${ }^{12} \mathrm{~A}$ published study reported that most hypertensive patients preferred not to split pills and that over 70\% of patients were willing to pay more for medications with dosages that they did not need to split. ${ }^{13}$ Limited published studies have addressed this drugrelated problem. In this study, we aimed to identify the effects of pill splitting on drug physiochemical properties and clinical outcomes among elderly cardiac patients.

\section{Methods}

\section{Study design}

A parallel design was adopted in this study. Patients were recruited from the Cardiac or Hypertension clinics of the Prince of Wales Hospital, Hong Kong. After medical records review, it was found that lisinopril, amlodipine, simvastatin, metformin, and perindopril were among the most commonly prescribed medications that required splitting in the two clinics. Therefore, patients who needed to split their pills when taking lisinopril, amlodipine, simvastatin, metformin, or perindopril were recruited. Patients were randomised into either group A (pill splitting with self-technique) or group $B$ (pill splitting with instructions and training) after their first clinic visit. All patients were asked to sign an informed consent form before enrolment. Group A patients were asked to split drugs using their own technique and continue until their next clinic visit. Group B patients were given proper instruction by pharmacists or pharmacy students on using pill cutters at their first visit and were asked to cut their pills accordingly until their next clinic visit. Patients watched a 2-minute video that explained the reasons for using pill cutters and described the proper way to open the pill cutter, position the drug in the pill cutter, clean the pill cutter, and store the split pills. Subsequently, the pharmacist answered patients' enquiries regarding the video or other questions related to pill splitting. The current study did not change any drug or dosage of the patient's existing treatment regimens. Follow-up clinic visits were scheduled with mean duration between first and follow-up clinic visits of $23.1 \pm 7.3$ weeks.

\section{Participants}

Chinese patients aged $\geq 65$ years, both male and female, and currently prescribed one or more of metformin, lisinopril, perindopril, amlodipine, or simvastatin (which require splitting) were included in the current study. Patients with dementia or severe physical limitations such as hemiplegia, blindness, or upper limb contractures were excluded from the study.

In our pilot study, we found that the change in

\section{藥丸分割訓練對老年人群的藥物理化性質、依從 性和臨床結局的影響：隨機試驗 \\ 李詠恩、李迪斯、方恩衍、甄秉言}

引言：本研究旨在提供香港老年心臟病患者進行藥丸分割訓練的臨床 和理化作用的信息。

方法: 採用平行研究設計, 納入威爾斯親王醫院服用賴諾普利、氨氯 地平、辛伐他汀、二甲雙胍或培哚普利時須將藥片分割所需劑量的患 者, 初診時將患者分為兩組。A組患者用自己的方法分割藥物, B組患 者接受藥丸分割器使用訓練後一直使用至下一次隨訪。主要結果是藥 丸分割器使用訓練前後藥物含量的變化, 並進行測定確定藥物含量。 次要結果是臨床結果的變化、患者對藥丸須分割服用的態度和接受程 度, 以及他們對藥丸分割服用的認識。

結果: 納入 193 例患者, 其中 101 例參與隨訪。分割藥丸落入測定限度 內的比例方面, $\mathrm{A}$ 組由初診的 $39.13 \%$ 增至隨訪時 $47.82 \%(\mathrm{P}=0.523)$, B組則由 $48.94 \%$ 增至 $51.06 \%(\mathrm{P}=1.000)$, 惟兩者均沒有統計學意 義。臨床結果方面, 患者的平均甘油三酸酯水平由初診的 $1.62 \pm 1.05$ 降至 $1.36 \pm 0.80 （ \mathrm{P}=0.049 ）$, 平均心率則由 $73.97 \pm 11.01$ 升至 $77.92 \pm 12.72 （ \mathrm{P}=0.026 ） 。$ 其他參數的變化均不明顯。

結論：這項研究強調分割藥丸後藥物含量的高變異性。根據受訪患者 的喜好, 服用母需分割劑量的藥丸會較為理想。如無可避免地須分割 藥丸, 應教育患者正確使用藥丸分割器。

drug assays of metformin, atenolol, and amlodipine varied from $52.7 \%$ to $147.2 \%$ after splitting. ${ }^{14}$ In our previously published study, systolic blood pressure decreased significantly (from $152.38 \pm 18.80 \mathrm{~mm} \mathrm{Hg}$ to $147.04 \pm 20.72 \mathrm{~mm} \mathrm{Hg}, \mathrm{P}=0.021$ ) after pharmacist intervention. ${ }^{15}$ The sample size for the primary outcome was calculated based on a population standard deviation of 0.75 , and that for the secondary outcomes was based on a population standard deviation of 0.85 . To achieve a $5 \%$ significance level and $80 \%$ power, 30 and 45 patients in each group would be needed for the primary and secondary outcomes, respectively. We expected a $10 \%$ dropout rate, and therefore, at least 80 patients were recruited for each group. There were 193 total participants in this study.

The participants were randomised into group A or B using a computerised dynamic allocation programme and stratification according to types of medications taken, sex, age, and visit dates to ensure balanced patient allocation. All operations were performed by the same pharmacist who conducted the survey.

\section{Outcome measures}

The primary outcome was the change of drug content before and after the pill splitting training. At baseline, patients in groups A and B were asked to split three tablets of the drugs that they were currently taking using their usual technique. At follow-up visit, group A patients were asked to split 
three tablets using their own technique, and group B patients were asked to split three tablets using a pill cutter. Two halved tablets were randomly selected for analysis each time. The halved tablets were weighed, and standard drug assays were performed. The drug content of metformin was assessed by ultravioletvisible spectrophotometry; that of amlodipine, simvastatin, and perindopril was assessed by ultraperformance liquid chromatography; and that of lisinopril was assessed by high-performance liquid chromatography.

The secondary outcomes were the changes in clinical outcomes between before and after the pill splitting training, including the change in blood pressure measurements, haemoglobin A1c, and

TABLE I. Patients' demographics at first (baseline) and follow-up clinic visits (mean duration $23.1 \pm 7.3$ weeks)*

\begin{tabular}{|c|c|c|}
\hline & Baseline $(n=193)$ & Follow-up $(n=101)$ \\
\hline \multicolumn{3}{|l|}{ Group } \\
\hline$A$ & $106(54.9 \%)$ & 47 (46.5\%) \\
\hline B & $87(45.1 \%)$ & $54(53.5 \%)$ \\
\hline \multicolumn{3}{|l|}{ Clinic } \\
\hline Cardiac & $154(79.8 \%)$ & $82(81.2 \%)$ \\
\hline Hypertension & $39(20.2 \%)$ & $19(18.8 \%)$ \\
\hline \multicolumn{3}{|l|}{ Gender } \\
\hline Female & $78(40.4 \%)$ & $36(35.6 \%)$ \\
\hline Male & $115(59.6 \%)$ & 65 (64.4\%) \\
\hline Mean age, y & $73.09 \pm 6.16$ & $72.03 \pm 5.53$ \\
\hline \multicolumn{3}{|l|}{ Education level } \\
\hline Less than primary & & $8(7.9 \%)$ \\
\hline Primary & & $26(25.7 \%)$ \\
\hline Secondary & & $23(22.8 \%)$ \\
\hline Tertiary or above & & $9(8.9 \%)$ \\
\hline \multicolumn{3}{|c|}{$\begin{array}{l}\text { Average monthly household income } \\
(\mathrm{HK} \$)\end{array}$} \\
\hline$<5000$ & & $46(45.5 \%)$ \\
\hline $5000-9999$ & & $5(5.0 \%)$ \\
\hline $10000-14999$ & & $4(4.0 \%)$ \\
\hline 15 000-19 999 & & $3(3.0 \%)$ \\
\hline $20000-24999$ & & $2(2.0 \%)$ \\
\hline 25 000-29999 & & 0 \\
\hline$\geq 30000$ & & $3(3.0 \%)$ \\
\hline \multicolumn{3}{|l|}{ Major caregiver } \\
\hline Self & & $80(79.2 \%)$ \\
\hline Spouse & & $7(6.9 \%)$ \\
\hline Self, spouse & & $2(2.0 \%)$ \\
\hline Children & & $2(2.0 \%)$ \\
\hline Domestic helper & & $2(2.0 \%)$ \\
\hline Social Welfare Department & & $1(1.0 \%)$ \\
\hline
\end{tabular}

* Data are shown as No. (\%) or mean \pm standard deviation cholesterol levels, the changes in patients' attitudes towards and acceptance of pill splitting, and the changes in patients' knowledge about pill splitting. Haemoglobin A1c and lipid levels were usually collected in hospital 1 week before patients' clinic visit. Upon initiating their clinic visits, patients had their blood pressures measured in the hospital's nurse station before they met their physicians. Blood pressure, haemoglobin A1c, and cholesterol levels were collected at baseline and at follow-up visit, and the patients' knowledge about and attitudes towards pill splitting were assessed by questionnaires.

\section{Statistical analysis}

Paired-samples $t$ tests were used for intra-group comparisons, and independent-samples $t$ tests were used for inter-group comparisons of mean tablet weight between before and after pill splitting training. Paired-samples $t$ tests were also used to assess the changes in clinical outcomes. McNemar's test was used for intra-group comparisons, and Fisher's exact test (two-sided) was used for intergroup comparisons of content uniformity, change in patients' acceptance towards pill splitting, and change in patients' knowledge about pill splitting. A $P$ value of $<0.05$ was considered statistically significant. All analyses were performed using the SPSS statistical programme (Windows version 25.0; IBM Corp, Armonk [NY], United States).

\section{Results \\ Participants}

A total of 193 eligible patients were enrolled on or before 17 January 2019, and they had follow-up visits on or before 30 April 2019. The patients were randomised into group $A(n=106)$ and group $B(n=87)$. A total of 101 patients participated, of whom 47 from group A and 54 from group B returned for follow-up visit. Among them, 46 patients from group A and 47 patients from group B provided samples for assay. The primary outcome analysis was conducted on those patients, and the secondary outcomes analysis was conducted on the 101 patients who returned for follow-up visit. The patients' demographic data are shown in Table 1.

\section{Drug content}

The primary outcome was the change of drug content between before and after the pill splitting training. Patients were asked to split three tablets during each visit. Two halved tablets were randomly selected as samples. The samples were weighed, and assays were performed. The mean weight of the halved tablets at baseline and at follow-up visit is documented in Table 2. Table 3 shows the percentage of halved tablets that were within the assay specifications at baseline and at follow-up visit. The percentage of 
samples with both halved tablets within range was from $1.62 \pm 1.05$ to $1.36 \pm 0.80 \mathrm{mmol} / \mathrm{L} \quad(\mathrm{P}=0.049)$, compared between groups A and B. In group A, whereas the mean heart rate increased significantly the percentage in range increased from $39.13 \%$ to from $73.97 \pm 11.01$ to $77.92 \pm 12.72 \mathrm{bpm}(\mathrm{P}=0.026)$. 47.82\% ( $\mathrm{P}=0.523)$, and the corresponding increase In group $\mathrm{B}$, there was also improvement in the for group B was from $48.94 \%$ to $51.06 \%(\mathrm{P}=1.000)$. mean diastolic blood pressure (from $73.40 \pm 14.39$ The difference in drug assay results between groups to $73.05 \pm 9.33 \mathrm{~mm} \mathrm{Hg}$ ), high-density lipoprotein $\mathrm{A}$ and $\mathrm{B}$ at baseline $(\mathrm{P}=0.406)$ and at follow-up visit (from $1.40 \pm 0.39$ to $1.46 \pm 0.44 \mathrm{mmol} / \mathrm{L}$ ), low-density $(\mathrm{P}=0.837)$ also did not reach statistical significance.

\section{Clinical outcomes}

lipoprotein (from $1.87 \pm 0.88$ to $1.85 \pm 0.73 \mathrm{mmol} / \mathrm{L}$ ), and total cholesterol (from $3.98 \pm 0.93$ to $3.91 \pm 0.85 \mathrm{mmol} / \mathrm{L})$, but those differences did The correlation between pill cutting training and not reach statistical significance. In the overall clinical outcomes is summarised in Table 4. The cohort, improvements were seen in diastolic blood mean triglyceride in group B decreased significantly pressure (from $74.21 \pm 12.47$ to $74.01 \pm 9.98 \mathrm{~mm} \mathrm{Hg}$ ),

TABLE 2. Mean weights of drug samples at first (baseline) and follow-up clinic visits (mean duration $23.1 \pm 7.3$ weeks)

\begin{tabular}{|c|c|c|c|c|c|c|c|c|c|c|}
\hline & \multicolumn{3}{|c|}{ Group A } & \multicolumn{3}{|c|}{ Group B } & \multicolumn{4}{|c|}{$P$ value } \\
\hline & & Baseline, $\mathbf{g}$ & Follow-up, g & & Baseline, $\mathbf{g}$ & Follow-up, $\mathbf{g}$ & $\begin{array}{c}\text { Group A: } \\
\text { baseline vs } \\
\text { follow-up }\end{array}$ & $\begin{array}{l}\text { Group B: } \\
\text { baseline vs } \\
\text { follow-up }\end{array}$ & $\begin{array}{c}\text { Baseline: } \\
\text { Group A } \\
\text { vs B }\end{array}$ & $\begin{array}{c}\text { Follow-up: } \\
\text { Group A } \\
\text { vs B }\end{array}$ \\
\hline Lisinopril & $\mathrm{n}=22$ & $0.0519 \pm 0.0126$ & $0.0518 \pm 0.0081$ & $n=24$ & $0.0518 \pm 0.0118$ & $0.0519 \pm 0.0086$ & 0.984 & 0.986 & 0.981 & 0.984 \\
\hline Perindopril & $\mathrm{n}=4$ & $0.0466 \pm 0.0072$ & $0.0469 \pm 0.0078$ & $n=8$ & $0.0452 \pm 0.0078$ & $0.0476 \pm 0.0071$ & 0.954 & 0.330 & 0.770 & 0.882 \\
\hline Amlodipine & $\mathrm{n}=58$ & $0.1034 \pm 0.0129$ & $0.1035 \pm 0.0144$ & $n=40$ & $0.1037 \pm 0.0181$ & $0.1044 \pm 0.0113$ & 0.946 & 0.866 & 0.911 & 0.766 \\
\hline Simvastatin & $\mathrm{n}=8$ & $0.0518 \pm 0.0064$ & $0.0524 \pm 0.0047$ & $n=22$ & $0.0523 \pm 0.0103$ & $0.0523 \pm 0.0051$ & 0.854 & 0.989 & 0.901 & 0.976 \\
\hline
\end{tabular}

TABLE 3. Number of halved tablets within assay specifications at first (baseline) and follow-up clinic visits (mean duration $23.1 \pm 7.3$ weeks)*

\begin{tabular}{|c|c|c|c|c|c|c|c|c|c|c|}
\hline & \multicolumn{3}{|c|}{ Group A } & \multicolumn{3}{|c|}{ Group B } & \multicolumn{4}{|c|}{$P$ value } \\
\hline & & Baseline & Follow-up & & Baseline & Follow-up & $\begin{array}{l}\text { Group A: } \\
\text { baseline vs } \\
\text { follow-up }\end{array}$ & $\begin{array}{l}\text { Group B: } \\
\text { baseline vs } \\
\text { follow-up }\end{array}$ & $\begin{array}{c}\text { Baseline: } \\
\text { Group A } \\
\text { vs B }\end{array}$ & $\begin{array}{c}\text { Follow-up: } \\
\text { Group A } \\
\text { vs B }\end{array}$ \\
\hline Lisinopril & $n=22$ & 5 (22.7\%) & $11(50.0 \%)$ & $n=24$ & 9 (37.5\%) & 12 (50.0\%) & 0.109 & 0.549 & 0.346 & 1.000 \\
\hline Perindopril & $\mathrm{n}=4$ & 2 (50.0\%) & $2(50.0 \%)$ & $n=8$ & $2(25.0 \%)$ & $5(62.5 \%)$ & 1.000 & 0.375 & 0.547 & 1.000 \\
\hline Amlodipine & $n=58$ & $39(67.2 \%)$ & 35 (60.3\%) & $n=40$ & 27 (67.5\%) & 27 (67.5\%) & 0.523 & 1.000 & 1.000 & 0.527 \\
\hline Simvastatin & $\mathrm{n}=8$ & 4 (50.0\%) & $6(75.0 \%)$ & $\mathrm{n}=22$ & 13 (59.1\%) & 17 (77.3\%) & 0.687 & 0.289 & 0.698 & 1.000 \\
\hline
\end{tabular}

* Data are shown as No. (\%), unless otherwise specified

TABLE 4. Change in clinical outcomes from first (baseline) to follow-up clinic visits (mean duration $23.1 \pm 7.3$ weeks)

\begin{tabular}{|c|c|c|c|c|c|c|c|c|c|c|c|c|}
\hline & \multicolumn{4}{|c|}{ Overall } & \multicolumn{4}{|c|}{ Group A } & \multicolumn{4}{|c|}{ Group B } \\
\hline & $\mathbf{n}$ & Baseline & Follow-up & $P$ value & $\mathbf{n}$ & Baseline & Follow-up & $P$ value & $\mathbf{n}$ & Baseline & Follow-up & $P$ value \\
\hline SBP & 73 & $129.53 \pm 16.94$ & $132.68 \pm 16.01$ & 0.121 & 33 & $128.97 \pm 13.51$ & $131.59 \pm 13.15$ & 0.262 & 40 & $129.75 \pm 19.55$ & $132.6 \pm 17.23$ & 0.365 \\
\hline DBP & 72 & $74.21 \pm 12.47$ & $74.01 \pm 9.98$ & 0.878 & 32 & $75.22 \pm 9.67$ & $75.22 \pm 10.77$ & 1 & 40 & $73.40 \pm 14.39$ & $73.05 \pm 9.33$ & 0.86 \\
\hline HR & 60 & $75.58 \pm 13.84$ & $78.22 \pm 12.25$ & 0.052 & 24 & $78 \pm 17.23$ & $78.67 \pm 11.76$ & 0.753 & 36 & $73.97 \pm 11.01$ & $77.92 \pm 12.72$ & 0.026 \\
\hline $\mathrm{HbA1c}$ & 37 & $6.54 \pm 0.98$ & $6.68 \pm 1.11$ & 0.174 & 12 & $6.42 \pm 0.70$ & $6.43 \pm 0.70$ & 0.897 & 25 & $6.6 \pm 1.10$ & $6.79 \pm 1.25$ & 0.156 \\
\hline HDL & 43 & $1.42 \pm 0.37$ & $1.43 \pm 0.40$ & 0.781 & 17 & $1.44 \pm 0.36$ & $1.36 \pm 0.34$ & 0.154 & 26 & $1.40 \pm 0.39$ & $1.46 \pm 0.44$ & 0.121 \\
\hline LDL & 43 & $1.79 \pm 0.84$ & $1.83 \pm 0.82$ & 0.718 & 17 & $1.68 \pm 0.80$ & $1.8 \pm 0.97$ & 0.545 & 26 & $1.87 \pm 0.88$ & $1.85 \pm 0.73$ & 0.931 \\
\hline TC & 45 & $3.90 \pm 0.97$ & $3.88 \pm 0.96$ & 0.784 & 19 & $3.79 \pm 1.04$ & $3.83 \pm 1.11$ & 0.846 & 26 & $3.98 \pm 0.93$ & $3.91 \pm 0.85$ & 0.565 \\
\hline $\mathrm{TG}$ & 45 & $1.46 \pm 0.91$ & $1.31 \pm 0.72$ & 0.078 & 19 & $1.24 \pm 0.63$ & $1.24 \pm 0.59$ & 1 & 26 & $1.62 \pm 1.05$ & $1.36 \pm 0.80$ & 0.049 \\
\hline
\end{tabular}

Abbreviations: DBP = diastolic blood pressure (mm Hg); HbAlc = haemoglobin Alc (\%); HDL = high-density lipoprotein (mmol/L); HR = heart rate (bpm); $\mathrm{LDL}=$ low-density lipoprotein ( $\mathrm{mmol} / \mathrm{L}) ; \mathrm{SBP}=$ systolic blood pressure $(\mathrm{mm} \mathrm{Hg}) ; \mathrm{TC}=$ total cholesterol $(\mathrm{mmol} / \mathrm{L}) ; \mathrm{TG}=$ triglyceride $(\mathrm{mmol} / \mathrm{L})$ 
TABLE 5. Patients' backgrounds, attitudes, and compliance rates*

\begin{tabular}{|c|c|}
\hline \multicolumn{2}{|c|}{ How many pills would you cut each time? $(n=101)$} \\
\hline Quantity for one dose & $28(27.72 \%)$ \\
\hline Quantity for 1 day & $2(1.98 \%)$ \\
\hline Quantity for 2 days to 1 week & $37(36.63 \%)$ \\
\hline Quantity for 1 week to 1 month & $27(26.73 \%)$ \\
\hline Quantity for more than 1 month & 7 (6.93\%) \\
\hline \multicolumn{2}{|c|}{$\begin{array}{l}\text { Have you been taught how to split pills properly by healthcare } \\
\text { staff? }(n=97)\end{array}$} \\
\hline Yes & $14(14.43 \%)$ \\
\hline No & $83(85.57 \%)$ \\
\hline \multicolumn{2}{|c|}{$\begin{array}{l}\text { Do you think that learning how to split pills correctly was helpful } \\
\text { to you? }(n=56)\end{array}$} \\
\hline Yes & $47(83.93 \%)$ \\
\hline No & $9(16.07 \%)$ \\
\hline \multicolumn{2}{|c|}{$\begin{array}{l}\text { How much money would you spend on buying a pill cutter }(H K \$) \text { ? } \\
(n=56)\end{array}$} \\
\hline$\$ 0$ & $6(10.71 \%)$ \\
\hline$\$ 1-10$ & $16(28.57 \%)$ \\
\hline$\$ 11-20$ & $16(28.57 \%)$ \\
\hline$\$ 21-50$ & $13(23.21 \%)$ \\
\hline$\$ 51-100$ & $4(7.14 \%)$ \\
\hline$>\$ 100$ & $1(1.79 \%)$ \\
\hline \multicolumn{2}{|c|}{$\begin{array}{l}\text { If pill splitting service were provided, would you be interested in } \\
\text { using this service? }(n=56)\end{array}$} \\
\hline Yes & $22(39.29 \%)$ \\
\hline No & $34(60.71 \%)$ \\
\hline \multicolumn{2}{|c|}{$\begin{array}{l}\text { How much would you be willing to spend on pill splitting service } \\
\text { each month? (HK\$) ( } n=22)\end{array}$} \\
\hline$\$ 0$ & $18(81.82 \%)$ \\
\hline$\$ 1-20$ & $4(18.18 \%)$ \\
\hline \multicolumn{2}{|c|}{ Proportion of patients finding pill splitting troublesome $(n=101)$} \\
\hline First visit & $30(29.70 \%)$ \\
\hline Follow-up visit & $25(24.75 \%)$ \\
\hline$P$ value & 0.063 \\
\hline \multicolumn{2}{|c|}{ No. of missed doses in the past 6 months $(n=94)$} \\
\hline Never & $60(63.83 \%)$ \\
\hline$<1$ per month & $21(22.34 \%)$ \\
\hline 1-2 per month & $13(13.83 \%)$ \\
\hline
\end{tabular}

* Data are shown as No. (\%), unless otherwise specified

high-density lipoprotein (from $1.42 \pm 0.37$ to $1.43 \pm 0.40 \mathrm{mmol} / \mathrm{L}$ ), total cholesterol (from $3.90 \pm 0.97$ to $3.88 \pm 0.96 \mathrm{mmol} / \mathrm{L}$ ), and triglyceride (from $1.46 \pm 0.91$ to $1.31 \pm 0.72 \mathrm{mmol} / \mathrm{L}$ ), but the changes did not reach statistical significance.

\section{Patients' backgrounds, attitudes, and knowledge}

In total, $57.43 \%$ of patients split their pills with their bare hands, followed by pill cutters (24.75\%), knives
(13.86\%), and scissors (10.89\%). The major reasons for not using pill cutters included: (1) the current method could split pills evenly (68.18\%), (2) using pill cutters was time consuming (34.09\%), and (3) the pills could not be split evenly by pill cutters (15.91\%). The major reasons for using pill cutters included: (1) pills could be cut evenly (80.95\%) and (2) the patient was able to exert force more easily (33.33\%). In total, $29.70 \%$ and $24.75 \%$ of patients found pill splitting troublesome at baseline and at follow-up visit, respectively (the difference was not significant, $\mathrm{P}=0.063$ ). The three major problems encountered by patients while splitting pills were (1) difficulty splitting the pills evenly (17.00\%), (2) the pills easily fragmented $(10.00 \%)$, and (3) difficulty seeing the pills clearly, as they were too small (9.00\%). Overall, $61.00 \%$ of the patients claimed that they had no difficulties. Nevertheless, $98.21 \%$ preferred to take tablets with exact dosages so that no splitting would be required. Patients' responses to other questions are listed in Table 5.

Table 6 shows that a significantly higher portion of patients in group B had a correct understanding of the following three questions after training: 'Using pill cutters allows pills to be divided into more accurate doses' (from $7.41 \%$ to $31.48 \%$; $\mathrm{P}=0.002$ ); 'The pills should be put into the triangular tip of the pill cutter' (from $9.26 \%$ to $31.48 \% ; \mathrm{P}=0.008$ ); and 'Pill cutters should be stored in a cool and dry place, away from sun or moisture' (from 9.26\% to $35.19 \%$; $\mathrm{P}=0.003$ ). In contrast, patients in group A did not show a statistically significant improvement in their understanding of any question. During the interview and evaluation of patients' knowledge about pill splitting at baseline and at follow-up visit, we did not detect any patients with major physical or cognitive abnormalities.

\section{Discussion}

Tablet splitting is a common practice in in-patient and out-patient settings, ${ }^{16}$ and it may be desirable in terms of dose adjustment, cost saving, and ease of swallowing., ${ }^{3,11,12,17-20}$ Nevertheless, it has been reported that splitting pills may cause drug instability, loss of drug due to powdering, uneven dosage, and reduced drug strength. ${ }^{21,22}$ It is generally understood that using tablet splitting devices can provide a more consistent dose. ${ }^{10,21}$ Previous studies have identified some characteristics that might affect the quality of halved tablets. Coated, unscored, and small tablets were found to be more difficult to cut. ${ }^{23}$ Individual pill cutting skill was another crucial factor that determined tablets' uniformity. ${ }^{23}$ In the current study, only $24.75 \%$ of patients split pills using pill cutters, and only $14.43 \%$ of patients had received pill splitting training. Therefore, it is likely that the drug content in the halved tablets did not reach assay standards. 
TABLE 6. Change in patients' knowledge about pill splitting at first (baseline) and follow-up clinic visits (mean duration $23.1 \pm 7.3$ weeks)*

\begin{tabular}{|c|c|c|c|c|c|c|}
\hline \multirow[t]{2}{*}{ Postoperative day } & \multicolumn{3}{|c|}{ Group A $(n=47)$} & \multicolumn{3}{|c|}{ Group B $(n=54)$} \\
\hline & Baseline & Follow-up & $P$ value & Baseline & Follow-up & $P$ value \\
\hline All pills can be cut & $8.51 \%$ & $12.77 \%$ & 0.754 & $12.96 \%$ & $14.81 \%$ & 1.000 \\
\hline Different pills should be kept together after cutting & $36.17 \%$ & $29.79 \%$ & 0.664 & $31.48 \%$ & $18.52 \%$ & 0.167 \\
\hline $\begin{array}{l}\text { Doctors' or pharmacists' opinions should be } \\
\text { sought before cutting any pills }\end{array}$ & $72.34 \%$ & $59.57 \%$ & 0.307 & $77.78 \%$ & $79.63 \%$ & 1.000 \\
\hline $\begin{array}{l}\text { Pill cutters are suitable for cutting pills with } \\
\text { different shapes }\end{array}$ & $19.15 \%$ & $19.15 \%$ & 1.000 & $7.41 \%$ & $12.96 \%$ & 0.508 \\
\hline $\begin{array}{l}\text { Using pill cutters allows pills to be divided into } \\
\text { more accurate doses }\end{array}$ & $40.43 \%$ & $36.17 \%$ & 0.774 & $7.41 \%$ & $31.48 \%$ & 0.002 \\
\hline $\begin{array}{l}\text { Pill cutters can be cleaned by dish washer or } \\
\text { sponge }\end{array}$ & $6.38 \%$ & $0.00 \%$ & 0.250 & $0.00 \%$ & $3.70 \%$ & 0.500 \\
\hline $\begin{array}{l}\text { Pill cutters can be bought from community } \\
\text { pharmacies }\end{array}$ & $23.40 \%$ & $25.53 \%$ & 1.000 & $7.41 \%$ & $11.11 \%$ & 0.727 \\
\hline $\begin{array}{l}\text { To clean a pill cutter, we should soak it into soap } \\
\text { and rinse it with water }\end{array}$ & $19.15 \%$ & $10.64 \%$ & 0.388 & $1.85 \%$ & $1.85 \%$ & 1.000 \\
\hline $\begin{array}{l}\text { The pills should be put inside the pill cutter's } \\
\text { triangular tip }\end{array}$ & $40.43 \%$ & $40.43 \%$ & 1.000 & $9.26 \%$ & $31.48 \%$ & 0.008 \\
\hline $\begin{array}{l}\text { Pill cutters should be stored in a cool, dry place, } \\
\text { away from sun or moisture }\end{array}$ & $42.55 \%$ & $38.30 \%$ & 0.791 & $9.26 \%$ & $35.19 \%$ & 0.003 \\
\hline
\end{tabular}

* Percentage refers to the percentage of patients who answered 'yes' to the question

Previous studies mainly focused on the weight deviations among halved tablets, not on drug content. ${ }^{21,22}$ One study showed that more than onethird of sampled half-tablets did not meet the United States Pharmacopeia specifications. ${ }^{24}$ The measured drug content variations among half-tablets were: warfarin sodium $(90.01 \%-109.40 \%)$, simvastatin (95.21\%-111.35\%), metoprolol succinate (82.77\%$115.92 \%)$, metoprolol tartrate (94.83\%-112.37\%), citalopram (96.50-111.93\%), and lisinopril (81.15\%$125.72 \%)$. In another study, five of eight drugs failed to meet European Pharmacopoeia recommendations for tablet weight deviation after splitting, with $25 \%$ of samples deviating by $>15 \%$ and $10 \%$ of samples deviating by $>25 \% .^{23}$ The study drugs used were phenobarbitone (maximum deviation: $80.45 \%$ ), digoxin (maximum deviation: 56.69\%), chloroquine (maximum deviation: 48.97\%), atenolol (maximum deviation: 45.37\%), and doxycycline (maximum deviation: $43.97 \%)$. In the present study, both halves of the tablet were within the assay standard at baseline for $39.13 \%$ and $48.94 \%$ of the patients in groups A and $\mathrm{B}$, respectively. After training, this percentage increased to $47.82 \%$ and $51.06 \%$, respectively, but the improvement was not significant, and the percentage of tablets in range was still relatively low. The results corroborated those of previous studies.

Few studies have examined the effect of patient education on the drug content of split pills. ${ }^{25,26}$ In the current study, we found no significant improvement in content uniformity after pill splitting training. This may be because our patients were elderly patients who may not have been able to perform the task well after a single training session. Content uniformity after pill splitting may be improved if pills are split by pharmacists or qualified staff. A study of paediatric pharmacists suggested that tablets $>8 \mathrm{~mm}$ could be split once to achieve an approximate half dose for paediatric use. ${ }^{27}$ Another study found a significant difference in splitting accuracy between nurses and laypersons. ${ }^{23}$ Nevertheless, only $39.29 \%$ of that study's patients were eager to partake of pill splitting service, and only $18.18 \%$ were willing to pay extra money for it. Therefore, pill cutting service may not be practical without a financial incentive.

Triglyceride levels decreased significantly and heart rate increased significantly in group B patients after the intervention. Nevertheless, we did not evaluate the patients' diet consumption or exercise levels, which may impact their triglyceride levels. No significant change in clinical outcomes was observed in other groups or other parameters. Because the studied drugs were lisinopril, perindopril, simvastatin, and amlodipine, which are not narrow-therapeutic-index drugs, these results were predictable and coincide with other studies that concluded that drugs with long halflife and wide therapeutic index are less likely to be affected. ${ }^{20,28}$ In view of the high variability of blood pressure measurements in the clinic, all patients were originally instructed to conduct daily blood pressure measurements at home using a portable blood pressure monitor. However, many patients did not measure their blood pressure daily or did not 
keep a proper self-record, so the clinical outcomes relied on the readings at clinic visits, which may not be consistent with their usual readings. In addition, management of chronic diseases like hypertension, diabetes mellitus, and dyslipidaemia could be influenced by multiple factors, and 3 months was a relatively short period for observation. The effect of drug content deviation after splitting on clinical outcomes may be more obvious in antibiotics or drugs with narrow therapeutic index (eg, digoxin). ${ }^{23,29,30}$

In the current study, we focused on the effect of pill splitting on drug content. Nevertheless, pill splitting may have other effects on drugs. The pill may carry a bitter taste, as the coating is broken, and the active ingredients may be more susceptible to moisture after exposure. ${ }^{31}$ Over $70 \%$ of patients prepared a sufficient quantity of pills for more than 1 day each time. In total, $36.63 \%$ of patients cut for 2 days to 1 week, $26.73 \%$ cut for 1 week to 1 month, and $6.93 \%$ cut for more than 1 month each time. Exposing the cut pills for too long may increase the risk of crushing or cracking. ${ }^{19}$ In total, $83.93 \%$ of patients found pill splitting training helpful, and the intervention produced significant improvement in patients' knowledge about pill splitting. This study has identified the major difficulties encountered by patients and the reasons behind their choices. Those problems should be addressed in future patient education. More than half of patients split pills with their bare hands, and the majority of patients who did not use pill cutters thought their own methods could divide pills evenly and that the use of pill cutters was time consuming. The major obstacles patients faced were the difficulties in splitting pills evenly and that the pills fragmented easily. Overall, 98.21\% of patients preferred to take tablets with the exact dosage instead of splitting pills. Previous studies also found that dispensing the exact dosage would be more favourable..$^{23,32}$ Nevertheless, if pill splitting is unavoidable, pharmacists should encourage patients to split coated, unscored, or irregularly shaped tablets with pill cutters to reduce crushing or fragmenting. Pharmacists should also educate patients about the appropriate way to use and clean pill cutters and remind patients to seek doctors' or pharmacists' advice before cutting any pills..$^{21,23,33}$

This project has several limitations. First, the participants' dropout rate was high, which might result in attrition bias. Compared with group A, a higher proportion of group B patients returned for follow-up visits. The statistically significant improvement in clinical outcomes among group B patients might be caused by their higher awareness about their own health instead of the effectiveness of the pill splitting method. There were limited human resources to make phone calls to patients between the baseline and face-to-face follow-up visits, which could have served as a reminder for patients to attend follow-up visits and perform home monitoring of their blood pressure and their pill splitting methods.

Second, dietary consumption and exercise levels were not evaluated, even though they may affect the clinical outcomes. Third, participants' education level, household income, and major caregivers were not collected at baseline. Only approximately $65 \%$ of participants who attended follow-up visits provided such information. These confounding factors might affect patients' ability to understand and memorise the steps of using pill cutters, thus affecting the content uniformity of their split pills. The effects of patients' characteristics on their knowledge and pill splitting skills were not assessed in the current study.

\section{Conclusion}

This study revealed that content uniformity can hardly be achieved after pill splitting by patients. No significant difference in clinical outcomes was observed after pill splitting training. It is preferable for pills with doses that do not require splitting to be provided, considering the assay results and patients' preference. Currently, there is inadequate patient education about pill splitting. Pharmacists should educate patients to use pill cutters properly if splitting is inevitable.

\section{Author contributions}

Concept or design: VWY Lee, FYH Fong, BPY Yan. Acquisition of data: VWY Lee, FYH Fong, BPY Yan. Analysis or interpretation of data: JTS Li.

Drafting of the manuscript: JTS Li.

Critical revision of the manuscript for important intellectual content: VWY Lee.

All authors had full access to the data, contributed to the study, approved the final version for publication, and take responsibility for its accuracy and integrity.

\section{Conflicts of interest}

As an editor of the journal, BPY Yan was not involved in the peer review process. Other authors have disclosed no conflicts of interest.

\section{Acknowledgement}

We thank the technicians at the School of Pharmacy, The Chinese University of Hong Kong for carrying out the drug physiochemical tests and the staff at Prince of Wales Hospital for arranging the logistics for patient counselling.

\section{Funding/support}

This study was supported by the Health and Medical Research Fund, Food and Health Bureau, Hong Kong SAR Government (\#14152111). The funder had no role in study design, data collection/analysis/interpretation, or manuscript preparation.

\section{Ethics approval}

Ethical approval was obtained from The Joint Chinese University of Hong Kong-New Territories East Cluster 
Clinical Research Ethics Committee (Clinical trial registration no.: CREC Ref No. 2017.014). Patient consent was obtained upon enrolment. The trial protocol can be obtained as requested.

\section{References}

1. Quinzler R, Gasse C, Schneider A, Kaufmann-Kolle P, Szecsenyi J, Haefeli WE. The frequency of inappropriate tablet splitting in primary care. Eur J Clin Pharmacol 2006;62:1065-73.

2. Berg C, Ekedahl A. Dosages involving splitting tablets: common but unnecessary? J Pharm Health Serv Res 2010;1:137-41.

3. Rodenhuis N, De Smet PA, Barends DM. The rationale of scored tablets as dosage form. Eur J Pharm Sci 2004;21:3058.

4. Rodenhuis N, de Smet PA, Barends DM. Patient experiences with the performance of tablet score lines needed for dosing. Pharm World Sci 2003;25:173-6.

5. Stanković $I$, Pešić $M$, Lalić $M$. Breaking of tablets as a costsaving strategy. Timočki Medicinski Glasnik 2007;32:5-10.

6. Fischbach MS, Gold JL, Lee M, Dergal JM, Litner GM, Rochon PA. Pill splitting in a long-term care facility. CMAJ 2001;164:785-6.

7. Denneboom W, Dautzenberg MG, Grol R, De Smet PA. User-related pharmaceutical care problems and factors affecting them: the importance of clinical relevance. J Clin Pharm Ther 2005;30:215-23.

8. Peek BT, Al-Achi A, Coombs SJ. Accuracy of tablet splitting by elderly patients. JAMA 2002;288:451-2.

9. Duncan MC, Castle SS, Streetman DS. Effect of tablet splitting on serum cholesterol concentrations. Ann Pharmacother 2002;36:205-9.

10. Rindone JP. Evaluation of tablet-splitting in patients taking lisinopril for hypertension. JCOM Wayne PA 2000;7:22-30.

11. Gee M, Hasson NK, Hahn T, Ryono R. Effects of a tabletsplitting program in patients taking HMG-CoA reductase inhibitors: analysis of clinical effects, patient satisfaction, compliance and cost avoidance. J Manag Care Pharm 2002;8:453-8.

12. Fawell NG, Cookson TL, Scranton SS. Relationship between tablet splitting and compliance, drug acquisition costs, and patient acceptance. Am J Health Syst Pharm 1999;56:2542-5.

13. McDevitt JT, Gurst AH, Chen Y. Accuracy of tablet splitting. Pharmacotherapy 1998;18:193-7.

14. Lee VW, Yu Y, Tang L, Yan B. Impact of pill-splitting training on drug physiochemical properties, compliance and clinical outcomes in elderly population-a cross-over cohort study. Value Health 2013;16:A514.

15. Lee VW, Pang PT, Kong KW, Chan PK, Kwok FL. Impact of pharmacy outreach services on blood pressure management in the elderly community in Hong Kong. Geriatr Gerontol Int 2013;13:175-81.

16. Crawford DJ. Is tablet splitting safe? Nursing made incredibly easy 2011;9:18-20.

17. Cohen CI, Cohen SI. Potential savings from splitting newer antidepressant medications. CNS Drugs 2002;16:353-8.
18. Stafford RS, Radley DC. The potential of pill splitting to achieve cost savings. Am J Manag Care 2002;8:706-12.

19. Bachynsky J, Wiens C, Melnychuk K. The practice of splitting tablets: cost and therapeutic aspects. Pharmacoeconomics 2002;20:339-46.

20. Helmy SA. Tablet splitting: is it worthwhile? Analysis of drug content and weight uniformity for half tablets of 16 commonly used medications in the outpatient setting. J Manag Care Spec Pharm 2015;21:76-86.

21. Verrue C, Mehuys E, Boussery K, Remon JP, Petrovic M. Tablet-splitting: a common yet not so innocent practice. J Adv Nurs 2010;67:26-32.

22. Rosenberg JM, Nathan JP, Plakogiannis F. Weight variability of pharmacist-dispensed split tablets. J Am Pharm Assoc (Wash) 2002;42:200-5.

23. Elliott I, Mayxay M, Yeuichaixong S, Lee SJ, Newton PN. The practice and clinical implications of tablet splitting in international health. Trop Med Int Health 2014;19:754-60.

24. Hill SW, Varker AS, Karlage K, Myrdal PB. Analysis of drug content and weight uniformity for half-tablets of 6 commonly split medications. J Manag Care Pharm 2009;15:253-61.

25. Gharaibeh SF, Tahaineh L. Effect of different splitting techniques on the characteristics of divided tablets of five commonly split drug products in Jordan. Pharm Pract (Granada) 2020;18:1776.

26. Ashrafpour R, Ayati N, Sadeghi R, et al. Comparison of treatment response achieved by tablet splitting versus whole tablet administration of levothyroxine in patients with thyroid cancer. Asia Ocean J Nucl Med Biol 2018;6:108-12.

27. Andersson $\AA$, Lindemalm S, Eksborg S. Dividing the tablets for children-good or bad? Pharm Methods 2016;7:23-7.

28. Chou CL, Hsu CC, Chou CY, Chen TJ, Chou LF, Chou YC. Tablet splitting of narrow therapeutic index drugs: a nationwide survey in Taiwan. Int J Clin Pharm 2015;37:1235-41.

29. Simpson JA, Watkins ER, Price RN, Aarons L, Kyle DE, White NJ.Mefloquine pharmacokinetic-pharmacodynamic models: implications for dosing and resistance. Antimicrob Agents Chemother 2000;44:3414-24.

30. White NJ, Pongtavornpinyo W, Maude RJ, et al. Hyperparasitaemia and low dosing are an important source of anti-malarial drug resistance. Malar J 2009;8:253.

31. Margiocco ML, Warren J, Borgarelli M, Kukanich B. Analysis of weight uniformity, content uniformity and 30-day stability in halves and quarters of routinely prescribed cardiovascular medications. J Vet Cardiol 2009;11:31-9.

32. Madathilethu J, Roberts M, Peak M, Blair J, Prescott R, Ford JL. Content uniformity of quartered hydrocortisone tablets in comparison with mini-tablets for paediatric dosing. BMJ Paediatr Open 2018;2:e000198.

33. Allemann SS, Bornand D, Hug B, Hersberger KE, Arnet I. Issues around the prescription of half tablets in Northern Switzerland: the irrational case of quetiapine. Biomed Res Int 2015;2015:602021. 